\title{
Fecal Calprotectin Level in Term and Preterm Babies before and after Starting of Feeding \\ Mohammed Mahmoud Romih ${ }^{1}$, Eman M. M. El-hindawy ${ }^{1}$, Naglaa Ali Khalifaa ${ }^{2}$, Ahmed Mohammed Othman*1
}

Departments of ${ }^{1}$ Pediatrics and ${ }^{2}$ Clinical Pathology, Faculty of Medicine, Zagazig University, Sharkia, Egypt

*Corresponding author: Ahmed Mohammed Othman, Mobile: (+20) 01144959715, E-Mail: drmidomido223@ gmail.com

\begin{abstract}
Background: Fecal biomarkers (FCP) may be characterized by a superior diagnostic sensitivity as they are highly organ specific. Fecal calprotectin meets the criteria of a laboratory parameter suitable for the assessment of inflammatory bowel disease. Objective: To evaluate FCP levels in both preterm and full-term infants after start feeding and its relationship with the type of feeding, birth weight, and other clinical and laboratory parameters.

Patients and Methods: This study was carried out at the outpatient clinic of the Pediatric Department Zagazig University Hospitals on 88 infants during the period from October 2016 to October 2017.

Results: FCP levels increased in $100 \%$ of infants involved in the study after feeding. FCP levels have a wide range of variation from 82 to $425 \mu \mathrm{g} / \mathrm{g}$ before feeding and from 174 to $692 \mu \mathrm{g} / \mathrm{g}$ after feeding. A significant negative correlation between FCP levels before and after feeding with birth weight especially in the full-term group. A higher percentage of increase was observed in breastfeeding and ranged from 64.76 to $91.31 \%$, while formula-fed feeding ranged from 39.09 to $84.94 \%$.

Conclusion: FCP levels increased in all infants after feeding with a wide range of variations with no differences between infants born vaginally or with C-section. The FCP levels increased significantly with breastfeeding than formula-fed feeding.
\end{abstract}

Keywords: Fecal Calprotectin, Term, and Preterm Babies, Feeding.

\section{INTRODUCTION}

Initially called leukocyte L1, calprotectin is a 36 $\mathrm{kDa}$ calcium and zinc-binding protein that constitutes about $60 \%$ of soluble cytosol protein in human neutrophil granulocytes, and is found in monocytes, macrophages, and epithelial cells ${ }^{(\mathbf{1})}$.

Calprotectin is a member of the S100 family of calcium and zinc-binding proteins; it is the heterodimer of S100 A8/A9. It is found in neutrophils, monocytes, and some squamous epithelium cells. The complex accounts for up to $60 \%$ of the soluble protein content of the neutrophil cytoplasm. It is released by activation of leucocytes as a consequence of inflammatory diseases (2). S100 A8 is also called calgranulin A and myeloid-related protein 8 (MRP8), and S100A9 is called calgranulin B (MRP14). They both are linked to the innate immune system ${ }^{(3)}$.

Fecal calprotectin levels ranged from $3.9 \mu \mathrm{g} / \mathrm{g}$ to $971.8 \mu \mathrm{g} / \mathrm{g}$, and there was a significant increase in fecal calprotectin in the study group when compared to the control group $(334.3 \pm 236.6 \mu \mathrm{g} / \mathrm{g}$ vs. $42.0 \pm 38.2 \mu \mathrm{g} / \mathrm{g}$, respectively) with a moderate inverse significant correlation between fecal calprotectin and birth weight. Furthermore, there was a moderate, significant correlation between fecal calprotectin and duration of breastfeeding range. On the other hand, there was no correlation between fecal calprotectin and post-natal age, gestational age, or volume of feeding. A cut-off at the $67.0 \mu \mathrm{g} / \mathrm{g}$ level, with $100 \%$ sensitivity and $76.9 \%$ specificity, was considered ${ }^{(4)}$.

Calprotectin has bacteriostatic and fungistatic actions, as it can isolate manganese and zinc in their cells ${ }^{(5)}$; it also has several biological properties including antimicrobic and immunomodulatory activity, and it is released during cell activation (active release) or cell death (passive release). It has been suggested as a useful indicator to determine the severity of inflammation in the intestine ${ }^{(\boldsymbol{6})}$.

The most significant factors that affect fecal calprotectin (FCP) excretion include ante- and perinatal antibiotic treatment, the volume of enteral feeding, the occurrence of unplanned interruptions of enteral feeding, and the gastrointestinal bacterial colonization $^{(\mathbf{1})}$.

High fecal calprotectin (f-calprotectin) levels were shown to correlate with an increased turnover of leukocytes in the intestinal barrier and granulocyte migration towards the intestinal lumen. Hence, fcalprotectin has been proposed as a non-invasive marker of intestinal inflammation in inflammatory bowel disease in adults and children ${ }^{(7)}$. Another review points to the relevance and limitations of calprotectin determination in these clinical settings ${ }^{(8)}$.

Despite these high levels, the putative use of fecal calprotectin as a marker of gastrointestinal disease, particularly necrotizing enterocolitis (NEC), has been explored in several cohorts of preterm infants. However, due to the high inter-and intra-individual variations consistently observed by all authors, the determination of a cutoff value for f-calprotectin has remained an elusive goal, as cut-off values ranging from 200 to $2000 \mu \mathrm{g} / \mathrm{g}$ have been proposed ${ }^{(9)}$.

Earlier studies suggest f-calprotectin is higher in infants born by cesarean section, compared with vaginal delivery, and correlates positively with postnatal age and volume of enteral feeds, and 
negatively with antibiotic treatment. The latter factors are known to influence gut bacterial colonization, suggesting a possible relationship between the bacterial establishment and calprotectin levels in the neonatal period. Accordingly, Mohan et al. ${ }^{(10)}$ found that bifidobacterial supplementation was associated with a significant decrease in calprotectin level.

The current study aimed to evaluate FCP levels in both preterm and full-term infants after start feeding and its relationship with the type of feeding, birth weight, and other clinical and laboratory parameters.

\section{PATIENT AND METHODS}

This study Cohort study was carried out at the outpatient clinic of the Pediatric Department Zagazig University Hospitals on 88 infants during the period from October 2016 to October 2017.

\section{The infants were divided into two groups:}

Group A: 44 preterm infants ( 28 to 37 weeks GA) of both genders from birth until the $28^{\text {th }}$ day of life and with 28 to $<37$ weeks of gestation and showed any of the signs of feeding intolerance, admitted to the neonatal intensive care unit (NICU) in the Pediatric Department of Zagazig University Hospitals, and Group B: 44 term infants.

Sample Size: The mean of fecal calprotectin in fullterm patients $145 \pm 74 \mathrm{mg}$ and among preterm $106 \pm 47$ mg with CI $95 \%$ with the power test $80 \%$ using openEPI version 16 . The sample is calculated to be 88 cases (44 cases in each group).

Inclusion criteria: Preterm infants (28 to 37 weeks GA) of both genders from birth until the $28^{\text {th }}$ day of life and with 28 to $<37$ weeks of gestation, admitted to the neonatal intensive care unit (NICU), who showed any of the signs of feeding intolerance leafing to interruption of the current feeding regime, such as increased gastric residuals $(>50 \%)$ of the previous feeding, emesis, abdominal distension (increase in abdominal girth by $2 \mathrm{~cm}$ or more between feedings), bloody stool, diarrhea, and visible bowel loops.

Exclusion criteria: Neonates suffering from intestinal congenital anomalies

\section{All studies neonates were subjected to:}

History: Complete history taking.

Examination: Complete clinical and physical examination and measurement of fecal calprotectin level in term and preterm babies before and after starting feeding.

\section{Ethical considerations:}

Ethical approval of the study was obtained from the research ethics committee of the Faculty of Medicine of Zagazig University and a written informed parental consent also was obtained.

Methodology: F-calprotectin was determined using an ELISA assay in 88 samples obtained prospectively from 44 preterm and 44 term infants before and after starting feeding.
Stool samples preparation: One gram stool sample with $9 \mathrm{ml}$ PBS (concentration of $0.01 \mathrm{M}, \mathrm{PH} 7.4$ ), Samples should be operated at $4{ }^{\circ} \mathrm{C}$. Collect supernatant carefully after centrifugation for $20 \mathrm{~min}$ at $2000-3000 \mathrm{rpm}$, Aliquot the supernatant for ELISA assay and future use.

Calculation of results: Known concentrations of Human CALP standard and its corresponding reading OD is plotted on the log scale (x-axis) and the log scale (y-axis), respectively. The concentration of Human CALP in the sample is determined by plotting the samples O.D. on the Y-axis. The original concentration is calculated by multiplying the dilution factor.

Precision: Intra-assay Precision (Precision within an assay): 3 samples with low, middle and high-level Human CALP were tested 20 times on one plate, respectively. Inter-assay precision (precision between assays): 3 samples with low, middle and high-level Human CALP were tested 3 different plates, 8 replicates in each plate.

$\mathrm{CV}(\%)=\mathrm{SD} /$ meanX100

Intra-assay: $\mathrm{CV}<10 \%$

Inter-assay: $\mathrm{CV}<12 \%$

Assay range: $3 \mathrm{ng} / \mathrm{ml}-200 \mathrm{ng} / \mathrm{ml}$

\section{Statistical analysis}

All data were collected, tabulated, and statistically analyzed using SPSS 22.0 for windows (SPSS Inc., Chicago, IL, USA) \& MedCalc 13 for windows (MedCalc Software bvba, Ostend, Belgium). Data were tested for normal distribution using the Shapiro Walk test. Qualitative data were represented as frequencies and relative percentages. Chi-square test $\left(\chi^{2}\right)$ and Fisher exact was used to calculate the difference between qualitative variables as indicated. Quantitative data were expressed as mean \pm SD (Standard deviation) for parametric and median and range for non-parametric data. Independent T-test and Mann Whitney test were used to calculate the difference between quantitative variables in two groups for parametric and non-parametric variables respectively. Pearson's and Spearman's correlation coefficients were used for correlating normal and nonparametric variables respectively. The (+) sign was considered as an indication for direct correlation i.e. increase frequency of independent lead to increase the frequency of dependent \& (-) sign as an indication for inverse correlation i.e. increase frequency of independent lead to decrease the frequency of dependent, also we consider values near to 1 as strong correlation $\&$ values near 0 as weak correlation. The receiver operating characteristic (ROC) curve was constructed to permit the selection of threshold values for test results and comparison of different testing strategies. P-value $<0.05$ was considered significant. 
RESULTS

Table (1): Demographic data and clinical characteristics distribution of the two studied groups

\begin{tabular}{|c|c|c|c|c|c|}
\hline \multicolumn{2}{|c|}{ Variable } & Preterm $(n=44)$ & $\operatorname{Term}(n=44)$ & $t / \chi^{2}$ & $\boldsymbol{P}$ \\
\hline \multicolumn{2}{|c|}{ GA (weeks) Mean \pm SD } & $31.77 \pm 2.88$ & $39.18 \pm 1.4$ & $10.8 \bullet$ & .000 \\
\hline \multicolumn{2}{|c|}{ Postnatal age } & $4.7 \pm 4.3$ & $4.1 \pm 2.3$ & $.6 \bullet$ & .54 \\
\hline \multirow{2}{*}{ Sex } & Male & $28(63.6 \%)$ & $30(68.2 \%)$ & \multirow{2}{*}{$.101 *$} & \multirow{2}{*}{.750} \\
\hline & Female & $16(36.4 \%)$ & $14(31.8 \%)$ & & \\
\hline \multicolumn{2}{|c|}{ Birth weight $(\mathrm{kg})$ Mean \pm SD } & $2.08 \pm .709$ & $3.16 \pm .563$ & $5.589 \bullet$ & .000 \\
\hline \multirow{2}{*}{ Delivery } & C-section & $28(63.6 \%)$ & $32(72.7 \%)$ & \multirow{2}{*}{$.419^{*}$} & \multirow{2}{*}{.517} \\
\hline & Vaginal delivery & $16(36.4 \%)$ & $12(27.3 \%)$ & & \\
\hline \multirow{2}{*}{ Feeding type } & Breast feeding & $22(50 \%)$ & $26(59.1 \%)$ & \multirow{2}{*}{$.367 *$} & \multirow{2}{*}{.545} \\
\hline & Mixed & $22(50 \%)$ & $18(40.9 \%)$ & & \\
\hline
\end{tabular}

This table shows that demographic data of the studied subjects included 28 males and 16 females with mean GA 31.77 weeks, mean postnatal age 4.7 days and mean birth weight $2.08 \mathrm{~kg}$ for preterm group \& 30 males and 14 females with mean GA 39.18 weeks, mean postnatal age 4.1 days and mean birth weight $3.16 \mathrm{~kg}$ for term group. There is a statistically significant difference between the two studied groups as regard age and birth weight.

Table (2): Diagnosis frequency and laboratory parameters of the two studied groups

\begin{tabular}{|c|c|c|c|c|}
\hline & Preterm $(n=44)$ & $\operatorname{Term}(n=44)$ & $\chi^{2}$ & $P$ \\
\hline \multicolumn{5}{|l|}{ Diagnosis frequency } \\
\hline TTN & $6(13.6 \%)$ & $20(45.5 \%)$ & \multirow{7}{*}{19.7} & \multirow{7}{*}{.003} \\
\hline Pneumonia & $20(45.5 \%)$ & $12(27.3 \%)$ & & \\
\hline Cardiac disease & $16(36.4 \%)$ & $0(0 \%)$ & & \\
\hline Sepsis & $0(0 \%)$ & $4(9.1 \%)$ & & \\
\hline NJ & $0(0 \%)$ & $6(13.6 \%)$ & & \\
\hline Sepsis, NJ & $0(0 \%)$ & $2(4.5 \%)$ & & \\
\hline Apnea of prematurity & $2(4.5 \%)$ & $0(0 \%)$ & & \\
\hline \multicolumn{5}{|l|}{ Laboratory parameters } \\
\hline HB Mean \pm SD & $14.78 \pm 3.06$ & $13.85 \pm 1.85$ & 1.19 & .23 \\
\hline PLT Mean \pm SD & $161.1 \pm 103.92$ & $176.5 \pm 100.1$ & .49 & .62 \\
\hline TLC Mean \pm SD & $17.6 \pm 14.62$ & $13.65 \pm 5.34$ & 1.21 & .23 \\
\hline CRP Mean \pm SD & $15.4 \pm 27.46$ & $26.72 \pm 32.16$ & 1.25 & .21 \\
\hline
\end{tabular}

This table shows that pneumonia has the highest percentage diagnosis in the preterm group and TTN has the highest percentage diagnosis in the term group. There is a statistically significant difference between the two studied groups as regard different diagnosis. There is no statistically significant difference between the two groups regarding any of the laboratory parameters mentioned above.

Table (3): Fecal Calprotectin of the two studied groups

\begin{tabular}{|c|c|c|c|c|}
\hline Variable & Preterm $(\mathbf{n}=\mathbf{4 4})$ & Term $(\mathbf{n}=\mathbf{4 4})$ & t & $\boldsymbol{P}$ \\
\hline $\begin{array}{c}\text { Calprotectin before } \\
\text { feeding Mean } \pm \text { SD }\end{array}$ & $253.8 \pm 119.7$ & $246.5 \pm 121.4$ & .2 & .842 \\
\hline $\begin{array}{c}\text { Calprotectin after } \\
\text { feeding Mean } \pm \text { SD }\end{array}$ & $355.5(75-428)$ & $188.5(82-454)$ & & .538 \\
\hline $\begin{array}{c}\text { Percentage of increase } \\
\text { of FCP level }\end{array}$ & $371(125-628)$ & $298(174-6 \pm 131.5$ & $.692)$ & .62 \\
\hline
\end{tabular}

This table shows that there is no statistically significant difference between the two groups regarding calprotectin before and after starting feeding and the percentage of increase of FCP level. 
Table (4): Comparing Fecal Calprotectin levels between exclusive breastfed and formula-fed cases

\begin{tabular}{|c|c|c|c|c|}
\hline Variable & BF $(n=48)$ & Mixed $(n=40)$ & $\mathbf{t}$ & $P$ \\
\hline $\begin{array}{l}\text { Calprotectin before } \\
\text { feeding Mean } \pm \text { SD }\end{array}$ & $\begin{array}{c}150.7 \pm 39 \\
153(75-222) \\
\end{array}$ & $\begin{array}{c}369.4 \pm 53.6 \\
371(279-454) \\
\end{array}$ & 15.1 & .000 \\
\hline $\begin{array}{l}\text { Calprotectin after } \\
\text { feeding Mean } \pm \text { SD }\end{array}$ & $\begin{array}{c}253 \pm 54.7 \\
251(125-350)\end{array}$ & $\begin{array}{c}489 \pm 80.3 \\
474.5(372-692)\end{array}$ & 11.1 & .000 \\
\hline $\begin{array}{c}\text { Percentage of increase } \\
\text { of FCP level }\end{array}$ & $\begin{array}{c}39.6 \pm 13.1 \\
40.5(15-60.9)\end{array}$ & $\begin{array}{c}23.8 \pm 8.2 \\
23.6(8.6-38.6)\end{array}$ & 4.6 & .000 \\
\hline
\end{tabular}

This table shows that there is a statistically significant difference between breastfed and mixed fed cases regarding calprotectin level before and after starting feeding and percentage of increase of FCP levels with a relative increase in FCP levels in exclusively breastfed cases.

Table (5): Relation between Fecal Calprotectin levels and feeding intolerance.

\begin{tabular}{|c|c|c|c|c|}
\hline Variable & $\begin{array}{c}\text { Cases with feeding } \\
\text { tolerance }(\mathbf{n = 4 2})\end{array}$ & $\begin{array}{c}\text { Cases with feeding } \\
\text { intolerance }(\mathbf{n}=\mathbf{4 6})\end{array}$ & $\mathbf{t}$ & $\boldsymbol{P}$ \\
\hline $\begin{array}{c}\text { Calprotectin before } \\
\text { feeding Mean } \pm \text { SD }\end{array}$ & $\begin{array}{c}176.9 \pm 70.2 \\
170(75-374)\end{array}$ & $\begin{array}{c}317 \pm 116.1 \\
338(82-454)\end{array}$ & 4.7 & $\mathbf{. 0 0 0}$ \\
\hline $\begin{array}{c}\text { Calprotectin after } \\
\text { feeding Mean } \pm \text { SD }\end{array}$ & $\begin{array}{c}276.5 \pm 77.3 \\
281(125-469)\end{array}$ & $\begin{array}{c}436.7 \pm 134.3 \\
473(174-692)\end{array}$ & 4.7 & $\mathbf{. 0 0 0}$ \\
\hline $\begin{array}{c}\text { Percentage of } \\
\text { increase of FCP level }\end{array}$ & $\begin{array}{c}36.5 \pm 12.4 \\
36.5(19.4-60.9)\end{array}$ & $\begin{array}{c}28.7 \pm 13.8 \\
27.6(8.6-59.8)\end{array}$ & 1.9 & $\mathbf{. 0 5}$ \\
\hline
\end{tabular}

This table shows that there is a statistically significant difference between cases with feeding tolerance and case with feeding intolerance regarding calprotectin before and after starting feeding and the percentage of increase of FCP level with a relative increase in FCP levels in cases with feeding intolerance.

Table (6): Effect of antibiotic therapy on fecal calprotectin levels.

\begin{tabular}{|c|c|c|c|c|}
\hline Variable & No antibiotic $(\mathbf{n = 3 6})$ & $\begin{array}{c}\text { With antibiotic } \\
(\mathbf{n = 5 2})\end{array}$ & $\mathbf{t}$ & $\boldsymbol{P}$ \\
\hline $\begin{array}{c}\text { Calprotectin before } \\
\text { feeding Mean } \pm \text { SD }\end{array}$ & $\begin{array}{c}297.5 \pm 121 \\
330(75-454)\end{array}$ & $\begin{array}{c}181.7 \pm 77.6 \\
165(95-402)\end{array}$ & 3.5 & $\mathbf{. 0 0 1}$ \\
\hline $\begin{array}{c}\text { Calprotectin after } \\
\text { feeding Mean } \pm \text { SD }\end{array}$ & $\begin{array}{c}421 \pm 135.5 \\
454(125-692)\end{array}$ & $\begin{array}{c}271.8 \pm 77.3 \\
248(186-487)\end{array}$ & 4.2 & $\mathbf{. 0 0 0}$ \\
\hline $\begin{array}{c}\text { Percentage of } \\
\text { increase of FCP level }\end{array}$ & $\begin{array}{c}31.4 \pm 13.2 \\
29.7(8.6-59.8)\end{array}$ & $\begin{array}{c}33.8 \pm 14.4 \\
31.6(13.7-60.9)\end{array}$ & .5 & .5 \\
\hline
\end{tabular}

This table shows that there is a statistically significant difference between cases treated with antibiotic therapy and cases without antibiotic administration regarding calprotectin before and after starting feeding with a relative decrease in FCP levels with antibiotic administration.

Table (7): Relation between fecal calprotectin levels and mode of delivery.

\begin{tabular}{|c|c|c|c|c|}
\hline Variable & NVD $(n=28)$ & $\operatorname{CS}(n=60)$ & $\mathbf{t}$ & $\boldsymbol{P}$ \\
\hline $\begin{array}{l}\text { Calprotectin before } \\
\text { feeding Mean } \pm \text { SD }\end{array}$ & $\begin{array}{l}253.1 \pm 121.8 \\
284(75-452)\end{array}$ & $\begin{array}{c}248.8 \pm 120 \\
189.5(82-454)\end{array}$ & .1 & .9 \\
\hline $\begin{array}{l}\text { Calprotectin after } \\
\text { feeding Mean } \pm \text { SD }\end{array}$ & $\begin{array}{c}349.7 \pm 113.4 \\
382(125-495)\end{array}$ & $\begin{array}{c}365.2 \pm 147.3 \\
307.5(174-692)\end{array}$ & .3 & .7 \\
\hline $\begin{array}{c}\text { Percentage of increase } \\
\text { of FCP level }\end{array}$ & $\begin{array}{c}30.6 \pm 16.3 \\
25.6(8.6-60.9)\end{array}$ & $\begin{array}{c}33.2 \pm 12.4 \\
33.8(14.4-55.5)\end{array}$ & .5 & .6 \\
\hline
\end{tabular}

This table shows that there is no statistically significant difference between normal vaginal delivered cases and CS delivered cases regarding calprotectin before and after starting feeding and the percentage of increase of FCP level. 
Table (8): Relation between fecal calprotectin levels and prognosis.

\begin{tabular}{|c|c|c|c|c|}
\hline Variable & Recovery $(\mathrm{n}=68)$ & Death $(n=20)$ & $\mathbf{t}$ & $P$ \\
\hline $\begin{array}{l}\text { Calprotectin before } \\
\text { feeding Mean } \pm \text { SD }\end{array}$ & $\begin{array}{c}259.1 \pm 118.9 \\
215(75-454)\end{array}$ & $\begin{array}{c}219.6 \pm 121.3 \\
183(82-415)\end{array}$ & .9 & .3 \\
\hline $\begin{array}{r}\text { Calprotectin after } \\
\text { feeding Mean } \pm \text { SD }\end{array}$ & $\begin{array}{c}365.7 \pm 144.3 \\
343(125-692) \\
\end{array}$ & $\begin{array}{c}341.6 \pm 109 \\
307.5(174-485) \\
\end{array}$ & .5 & .5 \\
\hline $\begin{array}{c}\text { Percentage of } \\
\text { increase of FCP } \\
\text { level }\end{array}$ & $\begin{array}{c}30.3 \pm 12.3 \\
27.6(8.6-60.9)\end{array}$ & $\begin{array}{c}39.7 \pm 15.9 \\
40.3(14.4-59.8)\end{array}$ & 1.7 & .1 \\
\hline
\end{tabular}

This table shows that there is no statistically significant difference between recovered and dead cases regarding calprotectin before and after starting feeding and the percentage of increase of FCP level.

\section{DISCUSSION}

The current study included 44 preterm infants ( 28 to 37 weeks GA) and 44 term infants of both genders from birth until the $28^{\text {th }}$ day of life and with 28 to $<37$ weeks of gestation and showed any of the signs of feeding intolerance, admitted to the neonatal intensive care unit (NICU) in the Pediatric Department of Zagazig University Hospitals. Fecal calprotectin was determined using an ELISA assay in both groups.

Fecal calprotectin levels have been reported to be much higher during the first few weeks of life both in healthy full-term ${ }^{(\mathbf{1 1}, 12)}$ and preterm infants ${ }^{(13)}$ than in healthy adults ${ }^{(14)}$ and children ${ }^{(15)}$.

Regarding calprotectin concentrations in both pre-term and full-term infants before and after feeding, the current study showed that FCP levels increased in $100 \%$ of infants involved in the study after feeding. On contrary, Nissen et al. (16) reported that no difference was found between the preterm and full-term infants. While, many types of research support our results ${ }^{(17,18)}$, which may be supported by many theories for its explanation. Van Elburg et al. ${ }^{(19)}$, showing that intestinal permeability, as measured with the lactulose/mannitol test, was higher in preterm infants compared with full-term infants only during the first 72 hours of life leading to transepithelial migration of neutrophils and then normalized to the level of full-term neonates. This can explain the higher levels of calprotectin observed in the meconium in the first days of life in preterm infants as compared with later values in fecal samples ${ }^{(\mathbf{1 6} \text {, }}$ 20). This phenomenon, ending by the third trimester of life in a process named "closure" could explain the significant decrease in calprotectin levels starting from the end of the first trimester of life. Interestingly, preterm infants, although displaying a higher intestinal permeability, do not exhibit levels that are higher than full-term infants and no correlation is seen with the gestational age ${ }^{(21)}$.

The current study showed that fecal calprotectin levels have a wide range of variation from 82 to $425 \mu \mathrm{g} / \mathrm{g}$ before feeding and from 174 to $692 \mu \mathrm{g} / \mathrm{g}$ after feeding. In accordance, many studies showed high inter-individual variations ${ }^{(1}$, 12, 22). These variations may be attributed to the method of collection, in which the sample stayed in the baby's diaper. However, Olafsdottir et al. ${ }^{(23)}$ showed that this sampling method, in which some water is absorbed by the diaper, increases the calprotectin concentration by no more than $30 \%$, a variation far lower than that measured in the different studies. Other hypotheses could be suggested. Because high fecal calprotectin in neonates reflects an increase in granulocytes in the intestinal lumen due to high intestinal permeability and/or development of the gut-associated lymphoid tissue, inter-individual variations should be linked to environmental factors, which could individually modify this process, that is, mode of feeding, intestinal colonization, or response to alimentary antigens ${ }^{(22)}$.

The results of the current study showed that there was a statistically significant difference between cases with feeding tolerance and case with feeding intolerance regarding calprotectin before and after starting feeding and the percentage of increase of FCP level with a relative increase in FCP levels in cases with feeding intolerance. Abnormal bacterial colonization may be a factor in feeding intolerance, especially in preterm neonates, mainly due to dysfunction of the intestinal barrier, the immune responses, and functions of the intestine ${ }^{\text {(24). }}$. It was concluded that preterm with feeding intolerance had statistically significant elevated levels of FCP compared to preterm infants without feeding intolerance ${ }^{(4)}$. Also, it may seem paradoxical to observe that a rise in calprotectin is observed in parallel with increased volume of enteral feeding, but a rise is also observed when there is a need to interrupt enteral feeding, i.e., in cases of poor digestive tolerance ${ }^{(\mathbf{1})}$.

Many studies have attempted to correlate fecal calprotectin levels in newborns with specific neonatal factors including gestation age, birth weight, type and volume of feeding, and feeding intolerance ${ }^{(4,25)}$. Although the factors that affect its excretion in neonates are incompletely known and remain controversial ${ }^{(\mathbf{2 0}, \mathbf{2 6})}$, the differences in FC levels across these studies may be influenced by genetic and environmental factors or a combination of both ${ }^{(27)}$. 
Regarding birth weight, the current study showed a significant negative correlation between FCP levels before and after feeding with birth weight, especially in the full-term group. In accordance, Rougé et al. (1), Kapel et al. ${ }^{(22)}$, and Moussa et al. ${ }^{(4)}$ reported a significant inverse correlation between FCP level and birth weight, and in disagreement with Campeotto et al. ${ }^{(28)}$ who found no significant correlation between birth weight and FCP. Lee et al. ${ }^{(12)}$ and Li et al. ${ }^{(21)}$ found that FCP levels were negatively correlated with birth weight and height $(\mathrm{r}=-0.41, \mathrm{P}<0.001)$, that growth was poorer with higher permeability values.

Previous studies have focused on the effect of the type of feeding on the level of FCP and the data are conflicting $\left(\mathbf{4},{ }^{29}\right.$. The current study reported that a higher percentage of increase was observed in breast feeding and ranged from 64.76 to $91.31 \%$, while in formula form feeding ranged from 39.09 to $84.94 \%$. Following the current study, Lee et al. ${ }^{(21)}$, Li et al. ${ }^{(21)}$ and Groer et al. ${ }^{(29)}$ described higher calprotectin levels in exclusively breast-fed infants compared with formula-fed ones. However, the comparison between the different studies is difficult because infants were recruited at various ages. On contrary, Oswari et al. ${ }^{(30)}$, Yoon et al. ${ }^{(31)}$, and Nakayuenyongsuk et al. ${ }^{(32)}$ found no differences between breast-fed and formula-fed infants during the first month of life in full-term infants in correlation with FCP levels. While Golden et al. ${ }^{(33)}$ found fecal calprotectin concentrations to be significantly lower in breastfed than in formula-fed infants during the "preweaning" period.

The current study showed that there is no statistically significant difference between normal vaginal delivered cases and CS delivered cases regarding calprotectin before and after starting feeding and the percentage of increase of FCP level. Otherwise, another study reported that FC levels in those born by vaginal delivery are higher than FC levels of cesarean section-born infants in accordance with Lee $\boldsymbol{e t} \boldsymbol{a l} .{ }^{(\mathbf{1 2})}$. It is generally accepted that the fetal gastrointestinal tract is sterile but that, soon after birth, the gastrointestinal tract becomes rapidly colonized by microorganisms in the delivery environment ${ }^{(34,35)}$. Natural vaginal delivery provides early contact with the maternal microbiome and is considered crucial for gut maturation, metabolic and immunologic programming, and host-microbe homeostasis establishment. Furthermore, in our study, mothers who delivered vaginally were more likely to breastfeed.

Also, no differences regarding gender as previously reported by Lee $\boldsymbol{e t}$ al. ${ }^{(12)}$ and Li et al. (21). While, the clinical demographic data were associated with FCP levels, which in agreement with Nakayuenyongsuk et al. ${ }^{(32)}$, and the ROC curve of fecal calprotectin as an indicator for recovery showed a good sensitivity of calprotectin, yet this cutoff level has a poor specificity as well, the same conclusion was reported by Rougé $\boldsymbol{e t} \boldsymbol{a l}$. (1).

Thus, high basal calprotectin levels in infancy could be due to higher intestinal permeability, the establishment of gut flora, and response to alimentary antigens, as well as to the colonization of the gut by commensal microbes. Therefore, the major potential sources of pioneer bacteria, and factors that may influence neonatal gut maturation, include in utero transmission of maternal flora to the fetal gut; delivery mode; type of feeding; postnatal age; environmental factors such as geographical location, familial environment, sanitary conditions can affect the FC levels in infancy ${ }^{(\mathbf{1 2})}$.

\section{CONCLUSION}

FCP levels increased in all infants after feeding with a wide range of variations with no differences between infants born vaginally or with $\mathrm{C}$-section. The FCP levels increased significantly with breastfeeding than formula-fed feeding. Also, low birth weight was conducted with high levels of FCP. Thus, many factors including birth weight, type of feeding, and type of delivery, have a strong relation with FCP levels in infants.

\section{REFERENCES}

1. Rougé C, Butel M, Piloquet $\mathrm{H}$ et al. (2010): Fecal calprotectin excretion in preterm infants during the neonatal period. PLoS One, 5(6): 11083.

2. Marshall W, Lapsley M, Day A et al. (2014): Clinical Biochemistry E-Book: Metabolic and Clinical Aspects. Elsevier Health Sciences. https://www.elsevier.com/books/clinicalbiochemistry-metabolic-and-clinicalaspects/marshall/978-0-7020-5140-1

3. Foell D, Wittkowski H, Roth J (2009): Monitoring disease activity by stool analyses: from occult blood to molecular markers of intestinal inflammation and damage. Gut, 58: (6): 859-868.

4. Moussa R, Khashana A, Kamel N et al. (2016): Fecal calprotectin levels in preterm infants with and without feeding intolerance. Jornal de Pediatria (Versão em Português), 92(5): 486-492.

5. Brophy M, Nolan M (2015): Manganese and microbial pathogenesis: sequestration by the Mammalian immune system and utilization by microorganisms. ACS Chemical Biology, 10(3): 641651.

6. Burri E, Beglinger C (2012): Faecal calprotectin: a useful tool in the management of inflammatory bowel disease. https://smw.ch/article/doi/smw.2012.13557

7. Konikoff M, Denson L (2006): Role of fecal calprotectin as a biomarker of intestinal inflammation 
in inflammatory bowel disease. Inflammatory Bowel Diseases, 12(6): 524-534.

8. Gisbert J, McNicholl A (2009): Questions and answers on the role of fecal calprotectin as a biological marker in inflammatory bowel disease. Digestive and Liver Disease, 41(1): 56-66.

9. Campeotto F, Kalach N, Lapillonne A et al. (2007): Time course of fecal calprotectin in preterm newborns during the first month of life. Acta Paediatrica, 96(10): 1531-1533.

10. Mohan R, Koebnick C, Schildt J et al. (2008): Effects of Bifidobacterium lactis Bb12 supplementation on body weight, fecal $\mathrm{pH}$, acetate, lactate, calprotectin, and $\operatorname{IgA}$ in preterm infants. Pediatric Research, 64(4): 418-22.

11. Zhu Q, Li F, Wang J et al. (2016): Fecal calprotectin in healthy children aged 1-4 years. PloS One, 11(3): 150725-29.

12. Lee Y, Min C, Choi Y et al. (2017): Delivery and feeding mode affects fecal calprotectin levels in infants $<7$ months old. Early Human Development, 108: 45-48.

13. Oord T, Hornung $\mathbf{N}$ (2014): Fecal calprotectin in healthy children. Scandinavian Journal of Clinical and Laboratory Investigation, 74(3): 254-258.

14. Tøn H, Brandsnes O, Dale $S$ et al. (2000): Improved assay for fecal calprotectin. Clinica Chimica Acta., 292(1-2): 41-54.

15. Fagerberg U, Lööf L, Myrdal U et al. (2005): Colorectal inflammation is well predicted by fecal calprotectin in children with gastrointestinal symptoms. Journal of Pediatric Gastroenterology and Nutrition, 40(4): 450-455.

16. Nissen A, van Gils $C$, Menheere $P$ et al. (2004): Fecal calprotectin in healthy term and preterm infants. Journal of Pediatric Gastroenterology and Nutrition, 38(1): 107-108.

17. Rugtveit J, Fagerhol M (2002): Age-dependent variations in fecal calprotectin concentrations in children. Journal of Pediatric Gastroenterology and Nutrition, 34(3): 323-27.

18. Fagerberg U, Lööf L, Merzoug R et al. (2003): Fecal calprotectin levels in healthy children studied with an improved assay. Journal of Pediatric Gastroenterology and Nutrition, 37(4): 468-472.

19. Van Elburg $R$, Fetter W, Bunkers C et al. (2003): Intestinal permeability in relation to birth weight and gestational and postnatal age. Archives of Disease in Childhood-Fetal and Neonatal Edition, 88(1): F52-F55.

20. Josefsson S, Bunn S, Domellöf M (2007): Fecal calprotectin in very low birth weight infants. Journal of Pediatric Gastroenterology and Nutrition, 44(4): 407413.

21. Li F, Ma J, Geng S et al. (2015): Fecal calprotectin concentrations in healthy children aged 1-18 months. PLoS One, 10(3): 119574-79.

22. Kapel N, Campeotto $\mathrm{F}$, Kalach $\mathrm{N}$ et al. (2010): Faecal calprotectin in term and preterm neonates.
Journal of Pediatric Gastroenterology and Nutrition, 51(5): 542-547.

23. Olafsdottir E, Aksnes L, Fluge G et al. (2002): Faecal calprotectin levels in infants with infantile colic, healthy infants, children with inflammatory bowel disease, children with recurrent abdominal pain, and healthy children. Acta Paediatrica, 91(1): 45-50.

24. Indrio F, Riezzo G, Cavallo $L$ et al. (2011): Physiological basis of food intolerance in VLBW. The Journal of Maternal-Fetal \& Neonatal Medicine, 24(1): 64-66.

25. Panczuk J, Unger S, Francis J et al. (2016): Introduction of bovine-based nutrient fortifier and gastrointestinal inflammation in very low birth weight infants as measured by fecal calprotectin. Breastfeeding Medicine, 11(1): 2-5.

26. Björkström M, Hall L, Söderlund S et al. (2009): Intestinal flora in very low- birth weight infants. Acta paediatrica, 98(11): 1762-1767.

27. Tamboli C, Richard F, Colombel J (2003): Fecal calprotectin in Crohn's disease: new family ties. Gastroenterology, 124(7): 1971-1974.

28. Campeotto $F$, Baldassarre $M$, Butel $M$ et al. (2009): Fecal calprotectin: cutoff values for identifying intestinal distress in preterm infants. Journal of Pediatric Gastroenterology and Nutrition, 48(4): 507510.

29. Groer M, Ashmeade T, Louis-Jacques A et al. (2016): Relationships of feeding and mother's milk with fecal calprotectin levels in preterm infants. Breastfeeding Medicine, 11(4): 207-212.

30. Oswari H, Prayitno L, Dwipoerwantoro $P$ et al. (2013): Comparison of stool microbiota compositions, stool alpha1- antitrypsin, and calprotectin concentrations, and diarrhoeal morbidity of Indonesian infants fed breast milk or probiotic/prebioticsupplemented formula. Journal of Paediatrics and Child Health, 49(12): 1032-1039.

31. Yoon JM, Park J, Ko K et al. (2014): Fecal calprotectin concentration in neonatal necrotizing enterocolitis. Korean Journal of Pediatrics, 57(8): 351356.

32. Nakayuenyongsuk $W$, Christofferson $M$, Stevenson D et al. (2018): Point-of-Care Fecal Calprotectin Monitoring in Preterm Infants at Risk for Necrotizing Enterocolitis. The Journal of Pediatrics, 196: 98-103.

33. Golden B, Bunn S, Main M (2002): Age-dependent variations in fecal calprotectin concentrations in children. Journal of Pediatric Gastroenterology and Nutrition, 34(3): 324-27.

34. Rutayisire E, Huang K, Liu Y et al. (2016): The mode of delivery affects the diversity and colonization pattern of the gut microbiota during the first year of infants' life: a systematic review. BMC gastroenterology, 16(1): 86-93.

35. Stokholm J, Thorsen J, Chawes B et al. (2016): Cesarean section changes neonatal gut colonization. Journal of Allergy and Clinical Immunology, 138(3): 881-889. 